\title{
Utilizing Dominant Early Maturity Genes of Sterile Line UP-3s in Hybrid Rice Breeding to Avoid High Temperature Season
}

\author{
Bihu Huang ${ }^{*}$, Zongbu Yan ${ }^{2,3}$ \\ ${ }^{1}$ Department of Agriculture, University of Arkansas at Pine Bluff, Pine Bluff, USA \\ ${ }^{2}$ Agri-Life Research, TAMU, Beaumont, USA \\ ${ }^{3}$ Guizhou Rice Research Institute, Guiyang, China \\ Email: ${ }^{*}$ huangb@uapb.edu
}

Received 25 August 2015; accepted 20 October 2015; published 23 October 2015

Copyright (C) 2015 by authors and Scientific Research Publishing Inc.

This work is licensed under the Creative Commons Attribution International License (CC BY). http://creativecommons.org/licenses/by/4.0/

\section{(c) (i) Open Access}

\section{Abstract}

A new sterile line UP-3s, which carries the Dominant Early Maturity Gene (DEMG), was bred on the farm of University of Arkansas at Pine Bluff (UAPB). UP-3s and two check sterile lines, Jin23-A and Xie-A which do not carry the Dominant Early Maturity Gene, were crossed with a group of different maturity restorer lines, PB-1R, PB-5R, PB11, PB-13R, PB-20, PB-21, PB-22R, and PB-23R. Eighteen new hybrid rice combinations of these crosses were then tested at UAPB in 2012 and 2013. The results showed that panicle differentiation (PD) of hybrids from female parent UP-3s (DEMG) crossed with the 8 male parents, were earlier than the hybrids from female parent Jin23-A or Xie-A crossed with the 8 male parents. The PD of these earlier hybrids was before Jun 25 and heading was before July 20. Early PD and heading avoided the high temperature (over $34^{\circ} \mathrm{C}$ ) period which usually occurs after July 20 in Arkansas. The yields of these earlier maturity hybrids with female parent UP-3s were higher than those of the late maturity hybrids thatwereF1 progeny of sterile lines Jin23-A or Xie-A (these two female parent checks with non-DEMG). These results showed that the DEMG sterile line UP-3s can be adopted in making crosses with later maturity restorer lines to obtain earlier maturity hybrids to avoid the high temperature period in Arkansas.

\section{Keywords}

Earlier Maturity, Dominant Gene, Sterile Line, Hybrid Rice, Utilization, Breeding, Avoid, High Temperature

\footnotetext{
${ }^{*}$ Corresponding author.
}

How to cite this paper: Huang, B.H. and Yan, Z.B. (2015) Utilizing Dominant Early Maturity Genes of Sterile Line UP-3s in Hybrid Rice Breeding to Avoid High Temperature Season. American Journal of Plant Sciences, 6, 2596-2602. 


\section{Introduction}

The rice heterosis (hybrid vigor) has been known for a long time in rice research and production. Utilization of hybrid rice is an important technology to meet the increasing rice demand in the world. Hybrid rice is more profitable and sustainable for yield in production. Hybrid rice delivers a per capita yield advantage of about $20 \%$ over inbred rice with lesser inputs to land, such as water and pesticides [1] (Rice-Tech, 2015). Also hybrid rice provides many other attributes in social and environmental aspects [1] (Rice-Tech, 2015). China is the first country to develop hybrid rice commercially. Hybrid rice research was initiated in 1964 [2] (Yuan, 1966). The essential genetic tools for breeding hybrid rice varieties, such as the male sterile line (A line), the maintainer line (B line) and restorer line (R line), were developed in 1973 [3] (Yuan and Virmani, 1988). The first batch of rice hybrid varieties was released commercially in 1976. Hybrid rice accounts for 50 percent of the total rice growing area, and 57 percent of the total rice output were from hybrid in China recent years. The research of hybrid rice in USA began in 1980s, and the first commercial hybrid rice was released in year 2000 by the Rice Tec company in USA [4] (David Bennett, 2010). Hybrid rice has been widely grown in the US, and now account for about 40\% of acreage in Arkansas rice production in 2012-2014 [5] [6] (Jarrod T. Hardke, 2014). UAPB initiated its in hybrid rice research in 2008 [7] (Huang, B. 2012). Many breeding materials have be developed, and used in the hybrid rice research activities.

A period of very hot weather usually occurs in the summer in Pine Bluff in Arkansas. There were about 50 days with daily highest temperature over $34^{\circ} \mathrm{C}$ from June 25-August 15 in 2012-2013 (Table 1). Rice panicle differentiation (PD) is very sensitive to high temperature. Rice heading usually occurs about 25 days after PD. The germplasm of earlier PD and heading may be away through avoidance to reduce heat-induced sterility at temperature above $34^{\circ} \mathrm{C}$. The best PD growing stage seems to be before June 25 and the heading stage will be before July 20 to avoid the high temperature in Pine Bluff, Arkansas. Therefore developing earlier maturity varieties are very important to the rice production in areas with very high summer temperature.

Breeding for early maturity hybrid rice is normally carried out by using the early maturity female sterile line crossed with an early maturity restore line. But this approach takes time and provides less diversified genetic materials. Another way is to use the sterile line with dominate early maturity gene (DEMG) as female crossed with different late maturity restorer line as male which is quicker, more effective and result in diversified genetics background from restorer materials.

A new sterile line UP-3s, which carries the Dominant Early Maturity Gene, was bred in University of Arkansas at Pine Bluff (UAPB). UP-3s came from Gobo (PI369806, a native rice variety of Surinam in South America)/Zhenshan 97//Xiangzaoxian No. 1, $\mathrm{F}_{6}$ generation. UP-3s is a sterile line (two line system) with DEMG. Its plant height is about $90 \mathrm{~cm}$ and heading days 85 days. The maturity date of its progeny hybrids, crossing with different restorer line, is depending on the maturity of female parent sterile line UP-3s. It can get the earlier hybrids by using this sterile line. Some early maturity hybrid rice combinations have been developed by usingUP-3s crossed with male parents of different late maturity restorer lines in UAPB rice research program 2011 and 2012. [7] [8] (Huang et al. 2012, 2015).

Xie-A is a sterile line with non-DEMG. Xie-A came from Ignape Catelo (PI 373138, a native rice variety of Senegal in Africa)/Xieqingzao//Xieqingzao, $\mathrm{B}_{6} \mathrm{~F}_{1}$ generation. Its plant height is $85 \mathrm{~cm}$, heading days is 75 days, and maturity dates of its progeny hybrids, crossing with different restorer line, are depending on the maturity of male parent (restorer lines). Late maturity hybrid rice combinations have been developed by using Xie-A crossed with male parents of different late maturity restorer lines in UAPB rice research program 2011.

Jin-23A also is a sterile line with non-DEMG. Jin-23A came from Ignape Catelo (PI 373138, a native rice variety of Senegal in Africa)/Jin-23//Jin-23, $\mathrm{B}_{6} \mathrm{~F}_{1}$ generation. Its plant height is about $80 \mathrm{~cm}$, the heading days is about 60 days, and maturity date of its progeny hybrids, crossing with different restorer line, are depending on the maturity of male parent (restorer lines). Late maturity hybrid rice combinations have been developed by using Jin23-A crossed with male parents of different late maturity restorer lines in UAPB rice research program 2012.

The two kinds of hybrids above were tested and compared for their agronomic traits and yield in UAPB farm in 2012 and 2013 separately under the weather condition described in Table 1.

\section{Materials and Methods}

Ten hybrids were developed from sterile lines UP-3s (DEMG) and Xie-A (Check, non-DEMG) by separately 
Table 1. The daily highest temperature at Pine Bluff from 2011-2013.

\begin{tabular}{|c|c|c|c|c|c|c|c|c|c|c|c|c|c|c|}
\hline Date & 2011 & 2012 & 2013 & Average & Date & 2011 & 2012 & 2013 & Average & Date & 2011 & 2012 & 2013 & Average \\
\hline 6_1 & 31.9 & 30.5 & 30.7 & 31.3 & 7_1 & 32.6 & 37.2 & 28.4 & 32.7 & 8_1 & 37 & 37.9 & 31.4 & 35.4 \\
\hline $6 \_2$ & 33.1 & 26.1 & 26.7 & 30 & 7_2 & 33.6 & 36.8 & 28.5 & 32.9 & 8_2 & 37.5 & 36 & 31.4 & 35.2 \\
\hline 6_3 & 33.9 & 32 & 24.9 & 30.3 & 7_3 & 34 & 33.1 & 29.1 & 32.1 & 8_3 & 39.5 & 35.2 & 33 & 35.9 \\
\hline 6_4 & 35.7 & 35.4 & 25.8 & 32.3 & 7_4 & 35.4 & 37.6 & 28.9 & 34 & 8_4 & 42.1 & 36.4 & 31.8 & 36.8 \\
\hline 6_5 & 35.9 & 29.6 & 26.9 & 30.8 & 7_5 & 35.8 & 38.1 & 29.7 & 34.5 & 8_5 & 38 & 37.7 & 32.6 & 36.1 \\
\hline 6_6 & 35.2 & 31.4 & 28.2 & 31.6 & 7_6 & 33.6 & 37.1 & 31.8 & 34.2 & 8_6 & 38.9 & 35.6 & 34.8 & 36.4 \\
\hline $6 \_7$ & 35.6 & 30.6 & 26.4 & 30.8 & 7_7 & 35.8 & 38.4 & 30.9 & 35 & 8_7 & 40.3 & 34.8 & 35.9 & 37 \\
\hline 6_8 & 35.3 & 29.3 & 27.6 & 30.7 & 7_8 & 32.2 & 37.7 & 32.8 & 34.2 & 8_8 & 39.9 & 35.6 & 34.9 & 36.8 \\
\hline 6_9 & 33.9 & 31.3 & 28.7 & 31.3 & 7_9 & 34.7 & 29.1 & 33.6 & 32.5 & 8_9 & 37.9 & 36.2 & 36.7 & 36.9 \\
\hline 6_10 & 33.9 & 32.3 & 29.3 & 31.8 & 7_10 & 35.3 & 30.7 & 34.3 & 32.7 & 8_10 & 32.8 & 36.4 & 35.1 & 34.8 \\
\hline 6_11 & 34.3 & 32.5 & 33.6 & 33.5 & 7_11 & 38.6 & 30.5 & 36.3 & 35.1 & 8_11 & 32.3 & 33.4 & 31.3 & 32.3 \\
\hline 6_12 & 34.7 & 34.8 & 35 & 34.8 & 7_12 & 37.8 & 29.4 & 34.5 & 33.9 & 8_12 & 27.4 & 29.9 & 35.6 & 31 \\
\hline 6_13 & 31.1 & 31.9 & 33.9 & 32.3 & 7_13 & 37.6 & 28.7 & 30.9 & 32.4 & 8_13 & 33.8 & 33.6 & 34.5 & 34 \\
\hline 6_14 & 36.3 & 30.5 & 34.5 & 33.8 & 7_14 & 35.2 & 29.1 & 29.7 & 31.3 & 8_14 & 29 & 36.2 & 28.9 & 31.4 \\
\hline 6_15 & 35.5 & 33.3 & 30.8 & 33.2 & 7_15 & 31.3 & 29.4 & 30.8 & 30.5 & 8_15 & 30.7 & 28.2 & 26.2 & 28.4 \\
\hline 6_16 & 34.9 & 33.6 & 30.6 & 33 & 7_16 & 33.8 & 30.2 & 32.2 & 32.1 & 8_16 & 29.5 & 30.3 & 25.4 & 28.4 \\
\hline 6_17 & 29.6 & 34.2 & 31.3 & 31.7 & 7_17 & 33.7 & 31.8 & 31.5 & 32.3 & 8_17 & 31.3 & 35.4 & 24.2 & 30.3 \\
\hline 6_18 & 35.1 & 33.5 & 28.2 & 32.3 & 7_18 & 31.7 & 33.7 & 34 & 33.1 & 8_18 & 35.5 & 31.3 & 27.2 & 31.3 \\
\hline 6_19 & 35.2 & 33.1 & 29.4 & 32.6 & 7_19 & 32.9 & 35.2 & 33.6 & 33.9 & 8_19 & 28.2 & 27.1 & 27.2 & 27.5 \\
\hline 6_20 & 36.1 & 33 & 30.9 & 33.3 & 7_20 & 33.6 & 36.8 & 32.8 & 34.4 & 8_20 & 34.8 & 28.8 & 30.1 & 31.3 \\
\hline 6_21 & 35 & 33 & 32.1 & 33.4 & 7_21 & 36.8 & 38.7 & 34.1 & 36.5 & 8_21 & 34.6 & 29.9 & 31.4 & 32 \\
\hline 6_22 & 32.6 & 34.1 & 33.1 & 33.3 & 7_22 & 36.6 & 33.3 & 33.1 & 34.3 & 8_22 & 30.7 & 30.5 & 33 & 31.4 \\
\hline 6_23 & 32.7 & 34.9 & 32.3 & 33.3 & 7_23 & 35.8 & 32.5 & 33.7 & 34 & 8_23 & 35.2 & 32.3 & 33.2 & 33.6 \\
\hline 6_24 & 35.8 & 36 & 32.7 & 34.8 & 7_24 & 36.6 & 33.8 & 32.2 & 34.2 & 8_24 & 36.3 & 32.2 & 33.3 & 33.9 \\
\hline 6_25 & 33.6 & 38.2 & 32.9 & 34.9 & 7_25 & 34.1 & 34.6 & 30.4 & 33.1 & 8_25 & 29.1 & 31.8 & 33.3 & 31.4 \\
\hline 6_26 & 36.5 & 40.7 & 32.6 & 36.6 & 7_26 & 35.4 & 35.4 & 29.2 & 33.3 & 8_26 & 33.6 & 31.5 & 32.2 & 32.4 \\
\hline 6_27 & 36.9 & 37.2 & 34.1 & 36.1 & 7_27 & 35 & 35.8 & 26 & 32.3 & 8_27 & 30.9 & 32.9 & 32.2 & 32 \\
\hline 6_28 & 36.3 & 37.7 & 35.9 & 36.6 & 7_28 & 35.4 & 32.1 & 28.3 & 31.9 & 8_28 & 32.1 & 33.6 & 32.6 & 32.8 \\
\hline 6_29 & 28.3 & 40.7 & 35.6 & 34.9 & 7_29 & 34.1 & 37.4 & 30.5 & 34 & 8_29 & 32.8 & 32 & 33.4 & 32.7 \\
\hline \multirow[t]{2}{*}{ 6_30 } & 33.3 & 39.6 & 32.2 & 35 & 7_30 & 31.8 & 36 & 31.5 & 33.1 & 8_30 & 30.9 & 34.1 & 34.2 & 33.1 \\
\hline & & & & & 7_31 & 35.2 & 40.7 & 31.6 & 35.8 & 8_31 & 33.9 & 27.6 & 35 & 32.2 \\
\hline
\end{tabular}

crossed with 5 restorer lines PB-1R, PB-11R, PB-13R, PB-20R, PB-21R in 2011. These 10 hybrids and their 7 parents were tested for agronomic traits and yield in the farm of UAPB in 2012. Soil texture is silt loam with PH value of 5.3. The test entries were sowed at April 18 in the greenhouse and transplanted to field 20 days after sowing with 10 feet long, 1 foot space row, and 3 replications for each entry. Weeds were controlled with 9.3 L ha-1 of propanil (3', 4'-dichloropropionanilide) mixed with $0.4 \mathrm{~kg} \cdot \mathrm{ha}^{-1}$ of quinclorac (3, 7-dichloroquinoline8-carboxylic acid; Facet, BASF) when the rice were about four-leaf stage. The nitrogen fertilizer was applied pre-flood at $134 \mathrm{~kg} \cdot \mathrm{N} \cdot \mathrm{ha}^{-1}$ at about the five-leaf stage. The flood (underground water from a well) was maintained throughout the growing season. Heading dates were recorded when $50 \%$ of the plants were headed. Pa- 
nicles were harvested 35 days after heading. Plant heights were measured at harvest. Weights of 100 grains and seed set rate were measured after harvest (seed set rate is the seeds percentage in total of spike lets per panicle), milled rice and head rice and yield were also measured.

Another 8 hybrids were developed from sterile lines UP-3s (DEMG) and Jin23-A (Check, non-DEMG) by separately crossed with 4 restorer lines PB-5R, PB-13R, PB-22R, PB-23R in 2012. These 8 hybrids and their 6 parents were tested for agronomic traits and yields in the farm of UAPB in 2013 in a same soil type and management as in 2012. The test entries were sowed in 3 different dates (April 11, 21 and May 1, respectively) in the greenhouse and transplanted to the field 20 days after each sowing date with 5 feet long, 1 foot space row, and 3 replications for each entry. Heading dates were recorded when $50 \%$ of the plants were headed. Panicles were harvested 35 days after heading. Plant heights were measured at harvest. Weights of 100 grains and seed set rate were measured after harvest.

Daily temperatures were recorded by Arkansas SCAN (Soil Climate Analysis Network) Site which is about 50 meters away from the field (Table 1). Yields had been analyzed by analysis of variance (ANOVA) among entries (lines) with Duncan multiple comparisons, and descriptive of means and standard errors for each entries (SAS program, $\mathrm{v} 12.0$ ).

\section{Results and Discussions}

In year 2012, the 4 hybrids (Table 2: UP-3s/PB-13R, UP-3s/PB-11R, UP-3s/PB-21R and UP-3s/PB20R), which were developed from sterile line UP-3s by crossed with late maturity restorer lines PB13R, PB11R, PB21R, and PB20R, headed between July 11-14 with 84 - 87 heading days (total days from sowing date to heading date), and their yields were 11,039, 10,985, 10,394, and 10,756 kg/hectare, respectively. The other 4 hybrids: Xie-A/ PB-1R, Xie-A/PB-13R, Xie-A/PB-11R, Xie-A/PB-21R and Xie-A/PB-20R which developed from check sterile line Xie-A by crossed with the same restorer lines, headed between July 22-31 with 95 - 104 heading days, and

Table 2. Hybrid rice yield test at UAPB 2012.

\begin{tabular}{|c|c|c|c|c|c|c|c|c|c|c|}
\hline \multirow{2}{*}{ Oder } & \multirow{2}{*}{$\begin{array}{l}\text { Cross, } \\
\text { parent }\end{array}$} & \multirow{2}{*}{$\begin{array}{l}\text { Heading date } \\
\text { month_date }\end{array}$} & \multirow{2}{*}{$\begin{array}{l}\text { Heading days } \\
\text { Sowing-heading }\end{array}$} & \multicolumn{2}{|c|}{ Yields } & \multirow{2}{*}{$\begin{array}{l}\text { Plant height } \\
\text { (cm) }\end{array}$} & \multirow{2}{*}{$\begin{array}{l}\text { Weight } \\
\text { g/100 grains }\end{array}$} & \multirow{2}{*}{$\begin{array}{l}\text { Seed set } \\
(\%)\end{array}$} & \multirow{2}{*}{$\begin{array}{l}\text { Milled rice } \\
\text { (\%) }\end{array}$} & \multirow{2}{*}{$\begin{array}{c}\text { Head rice } \\
\text { (\%) }\end{array}$} \\
\hline & & & & $\mathrm{kg} / \mathrm{h}$ & Std Error & & & & & \\
\hline 1 & Xie-A/PB-1R & 7_12 & 85 & $10,778 \mathrm{a}$ & 175.5 & 115 & 3.1 & 89.2 & 70.5 & 47.4 \\
\hline 2 & Xie-A/PB-13R & 7_22 & 95 & $9448 c$ & 83.4 & 117 & 3.2 & 80.6 & 70.1 & 49.5 \\
\hline 3 & Xie-A/PB-11R & 7_23 & 96 & $8588 \mathrm{e}$ & 127.9 & 126 & 3.1 & 83.8 & 72.1 & 50.3 \\
\hline 4 & Xie-A/PB-21R & 7_26 & 99 & 9026d & 51.7 & 122 & 3.2 & 82.1 & 74.4 & 52.3 \\
\hline 5 & Xie-A/PB-20R & 7_31 & 104 & 8512e & 100.4 & 121 & 3.3 & 81.9 & 74.8 & 54.3 \\
\hline 6 & UP-3s/PB-1R & 7_11 & 84 & $10,860 \mathrm{a}$ & 81.7 & 116 & 3.1 & 92.4 & 70.8 & 50.3 \\
\hline 7 & UP-3s/PB-13R & 7_11 & 84 & $11,039 a$ & 79.5 & 118 & 2.9 & 95.9 & 73.7 & 51.2 \\
\hline 8 & UP-3s/PB-11R & 7_12 & 85 & $10,985 a$ & 67.9 & 119 & 2.8 & 94.9 & 72.1 & 52.3 \\
\hline 9 & UP-3s/PB-21R & 7_12 & 85 & $10,394 b$ & 125.4 & 119 & 2.9 & 97 & 68.7 & 56.1 \\
\hline 10 & UP-3s/PB-20R & 7_14 & 87 & $10,756 a$ & 111.0 & 113 & 3.1 & 97 & 74.5 & 51.3 \\
\hline 11 & $\begin{array}{l}\text { Xie-A } \\
\text { (check) }\end{array}$ & 7_2 & 75 & & & & & & & \\
\hline 12 & UP-3s & 7_14 & 87 & & & & & & & \\
\hline 13 & PB-1R & 7_19 & 92 & 6908gh & 112.5 & 116 & 3.3 & 80.2 & 70.3 & 50.1 \\
\hline 14 & PB-13R & 8_2 & 106 & $7093 \mathrm{~g}$ & 61.7 & 99 & 3.4 & 76.9 & 71.4 & 46 \\
\hline 15 & PB-11R & 8_6 & 110 & $6729 \mathrm{i}$ & 39.9 & 93 & 3.1 & 75.4 & 72,2 & 54 \\
\hline 16 & PB-21R & 8_8 & 112 & 7711f & 175.7 & 107 & 3.2 & 75.9 & 69.6 & 46 \\
\hline 17 & PB-20R & 8_11 & 114 & 6832gh & 84.9 & 115 & 3.3 & 74.9 & 68.5 & 47 \\
\hline
\end{tabular}

Means with the same letters are not significant at $\alpha=0.05$. 
their yields were 9448, 8588, 9026, and 8512 kg/hectare, respectively. The yields of hybrid combinations developed from UP-3s were significantly higher than the yields of combinations developed from Xie-A (Table 2). The heading days and yields were similar for the hybrids UP-3s/PB-1R and Xie-A/PB-1R that were developed from sterile lines UP-3s and check Xie-A by crossed with the restorer line PB-1R due to PB-1R having early maturity gene. They headed in July 11-12 with 84 - 85 heading days, and yield 10,860 and 10,778 kg/hectare, respectively (Table 2).

The cross of UP-3/PB-13R matured 11 days earlier and yielded 16.8\% higher than the cross of Xie-A/PB-13R; The cross of UP-3s/PB11R matured 11 days earlier and yielded $27.9 \%$ higher than the cross of Xie-A/ PB-11R; The cross of UP-3s/PB-13R matured 14 days earlier and yielded 15.3\% higher than that cross of Xie-A/PB-21R; The cross ofUP-3s/PB-20R matured 14 days earlier and yielded 26.4\% higher than the cross of Xie-A/PB-20R. All these results are due to the UP-3s has DEMG, and Xie-A has no DEMG (Table 2).

The heading days and yield of the crosses UP-3s/PB1R and Xie-A/PB1R were similar because PB-1R is an earlier season restores line (Table 2).

In the year 2013, 4 hybrids (Table 3: UP-3s/PB-13R, UP-3s/PB-5R, UP-3s/PB-22R, and UP-3s/PB-23R), which were developed from Up-3s crossed with late maturity restorer lines PB-13R, PB-5R, PB-22R, and PB-23, headed between July 5-7 with 84 - 87 heading days in planting stage I (April 11); headed between July 12-14 with 82 - 84 heading days in planting stage II (April 21); and headed between July 18-20 with 78 - 80 heading days in planting stage III (May 1). The other 4 hybrids: Jin-23A/PB-13R, Jin-23A/PB-5R, Jin-23A/PB-22R, and Jin-23A/PB-23R, which were developed from check sterile line Jin-23A by crossed with the same group of restorer, headed between July 21-29 with 101 - 109 long heading days in the Stage I, between July 28-August 6 with 98 - 104 heading days in the stage II, and between August 4-August 13 with 95 - 104 heading days in the stage III. The 4 hybrids from Jin-23A had longer heading days there for matured later than the 4 hybrids from Up-3s (Table 3).

The yields of the crosses, UP-3s/PB-13R, UP-3s/PB-5R, UP-3s/PB-22R, and UP-3s/PB-23R, were 11,649, $17,980,11,725$, and 11,627 kg/h, respectively in planting Stage I, 11,009, 11,152, 10,928, and 11,073 kg/h, respectively in stage II, and 10,882, 10,919, 10,371, and 10,694 kg/h, respectively in stage III. Yields of the crosses, Jin-23A/PB-13R, Jin-23A/PB-5R, Jin-23A/PB-22R, and Jin23-A/PB-23R were only 9422, 9344, 9846, and $9637 \mathrm{~kg} / \mathrm{h}$, respectively in planting Stage I, 3979, 8948, 9489, and $9214 \mathrm{~kg} / \mathrm{h}$, respectively in stage II, and 8825, 8644, 8490, and $8272 \mathrm{~kg} / \mathrm{h}$, respectively in stage III. The average yields of UP-3s combinations were significantly higher than the yields of Jin-23A combinations of the three planting dates. The heading days and yields of cross UP-3/PB-13R were 16, 13, and 17 days earlier and 23.6\%, 17.4\%, and 23.3\% higher than the cross Jin-23A/PB-13R in planting stage I, II, and II, respectively. The heading days and yields of cross UP-3/ PB-5R were 17, 17, and 18 days earlier and 28.2\%, 24.6\%, and 26.3\% higher than the cross Jin-23A/PB-5R in stage I, II, and II, respectively. The heading days and yields of cross UP-3/PB-22R were 21, 19, and 22 days earlier and 19.1\%, 15.2\%, and 22.2\% higher than cross Jin-23 A/PB-21R in stage I, II, and III, respectively. The heading days and yields of cross ofUP-3s/PB-23R was 25 days, 24 days, and 25 days earlier and $20.6 \%, 20.2 \%$ and $29.3 \%$ higher than the cross Jin-23A/PB-23R in planting stage I, II, and III, respectively. All the results demonstrated that DEMG will make earlier PD and result earlier heading, and gain higher yields than NODEMG in this weather condition (Table 3).

The results suggest that earlier planting results in higher yields. The yields of hybrid UP-3s/PB-13R in the first stage were $5.8 \%$ and $7.1 \%$ higher than that in the second and the third stage, respectively; The yields of hybrid UP-3s/PB-5R planted in the first stage were $7.2 \%$ and $9.7 \%$ higher than that in the second and third stage, respectively; The yields of hybrid UP-3s/PB-22R planted in the first stage were $7.3 \%$ and $13.1 \%$ higher than that in the second and third stage, respectively; The yields of hybrid UP-3s/PB-23R in the first stage were $5.0 \%$ and 8.7\% higher than that in the second and third stage, respectively; The same trend also holds for the hybrids from Jin-23A, which does not have DEMG (Table 3).

These results showed that the early maturity hybrids with DEMG sterile female parent had higher yields than late maturity hybrids with non-DEMG sterile female parent, and the yield of earlier planting was higher than that late planting stage for the same hybrid. These results indicate that their PD (the panicle differentiation stage) had avoided the high temperature period. To achieve higher yield under the similar weather condition, the PD should be before June 25 and heading stage should be before July 20. The growing stage of a variety from sowing to heading should be earlier than 90 days to achieve higher yield in rice growing areas with high temperatures. 


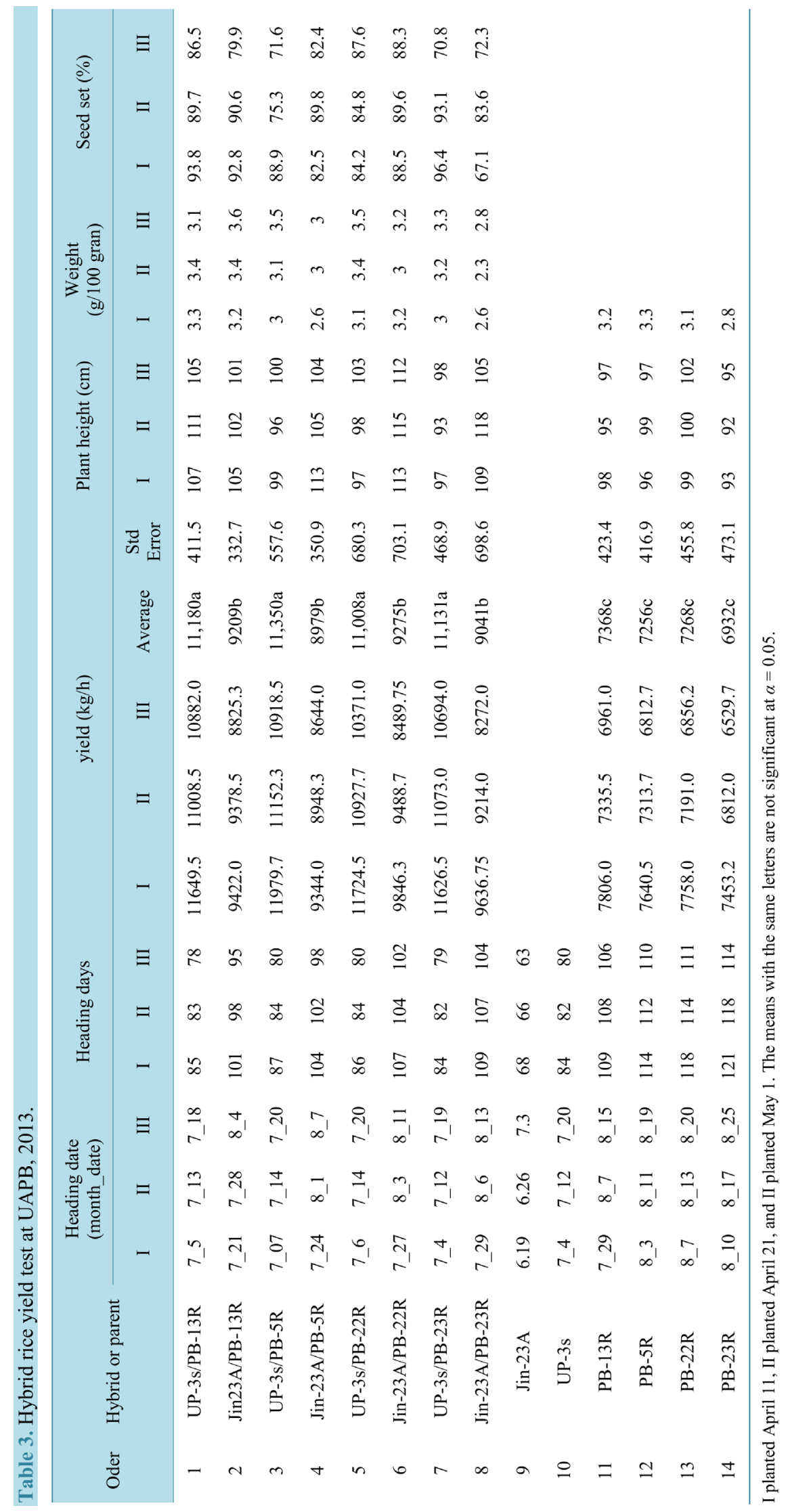


These results suggest that the better, quicker and more effective way to get the earlier maturity hybrids with the genetic diversity is to cross the DEMG sterile line with the late maturity restorer lines. The Up-3s is an excellent DEMG sterile line to make new early maturity hybrids with late maturity restorer line. This line and can be directly used in the hybrid rice seed production.

These results also suggest that the UP-3s is an ideal line to be used in new sterile line breeding through making crosses with other maintain lines and for screening new DEMG sterile lines in the breeding program.

These results suggest that the early PD and heading maybe one way to reduce heat-induce sterility at temperature above $34^{\circ} \mathrm{C}$. Late maturity restorer lines are normally used to make the late maturity hybrids with normal sterile lines, but they can also be used to breed early maturity hybrids through crossing with DEMG sterile line such as UP-3s which is quicker, more effective and can result in diversified genetic background from restorer materials. This technology could greatly contribute to hybrid rice breeding and seed production in the future.

\section{References}

[1] Rice Tec. Product Guide 2015. www.ricetec.com

[2] Yuan, L.P. (1966) A Preliminary Report on Male Sterility in Rice. Science Bulletin, 4, 32-34.

[3] Yuan and Virmani (1988) Status of Hybrid Rice Research and Development. Manila, Phlippines. IRRI.

[4] Bennett, D. (2010) Hybrid Rice Varieties—Range of Options. Delta Farm Press, Saint Charles.

[5] Hardke, J.T. (2014) Arkansas Harvested Rice Acreage Summary Preliminary Report. http://www.arkansas-crops.com/wp-content/uploads/2014/12/2014-Rice-Harvest-Acreage-Summary-Table-Preliminary .pdf

[6] Hardke, J.T. (2014) Trends in Arkansas Rice Production, 2013. University of Arkansas Agricultural Experiment Station Research Series 617, Fayetteville, Ark, 13-23.

[7] Huang, B., Yan, Z., Deren, C.W., Yan, W. and Mc Cung, A. (2012) Evaluation of Male Sterile Lines of Hybrid Rice at UAPB Farm. 34th Rice Technical Working Group, Hot Spring, AR, February 2012.

[8] Huang, B.H., Yan, Z.B., Yan, W.G. and Deren, C. (2015) Changes of Sterility to Some Two Line System Male Sterilers in Different Rice Growing Seasons at Pine Bluff, AR USA. Accepted by Southwest China Journal of Agricultural Sciences. 